\title{
¿Dónde aprendo o enseño mejor? Concurso de imágenes fijas UNAM 2019
}

\author{
Julio Arnoldo Prado Saavedra y Patricia González Flores
}

Entre marzo y junio de 2019, se realizó el concurso universitario de imágenes fijas "Espacios de aprendizaje y enseñanza de la comunidad UNAM", con la intención de documentar la perspectiva de la comunidad universitaria sobre los espacios de enseñanza y aprendizaje que prefieren, incluyendo a los estudiantes y a los docentes. Se buscó reconocer esos lugares, promover la reflexión universitaria sobre sus prácticas de estudio y docencia, ampliar los ámbitos de expresión creativa y brindar información para el diseño de futuros espacios.

La convocatoria se lanzó el 25 de marzo de 2019, la recepción de trabajos del 1 de abril al 4 de mayo. Se recibieron 56 trabajos provenientes de 40 entidades académicas de la unAm, con aportaciones de diversos niveles y regiones, lo cual contribuye al enriquecimiento de los diálogos colectivos. Los resultados se dieron a conocer el 7 de junio y la premiación ocurrió el 14 de junio. Te invitamos a acercarte a las imágenes ganadoras. 


\section{Julio Arnoldo Prado Saavedra}

Especialista en tecnología y matemática educativa y contenidos digitales con más de 13 años de experiencia en planeación y desarrollo de proyectos educativos en instituciones públicas y privadas. Matemático por la UNAM, con Mención de Honor Sotero Prieto por la Sociedad Matemática Mexicana. Cursó la Maestría en Ciencias de la Complejidad en la UACM. Maestrante de la Maestría en Tecnología e Innovación Educativa por el Instituto Tecnológico y de Estudios Superiores de Monterrey. Actualmente es Coordinador de Estrategias de Enseñanza-Aprendizaje de la Coordinación de Desarrollo Educativo e Innovación Curricular.

\section{Patricia González Flores}

patgonzalez@unam.mx

Especialista en tecnología educativa y educación a distancia con más de 20 años de experiencia en implementación de proyectos educativos en instituciones públicas y privadas. Licenciada en Pedagogía por la Universidad Nacional Autónoma de México (UNAM) y maestra en Medios de Comunicación por The New School. Funge actualmente como Subdirectora de Innovación Educativa de la Coordinación de Desarrollo Educativo e Innovación Curricular. 

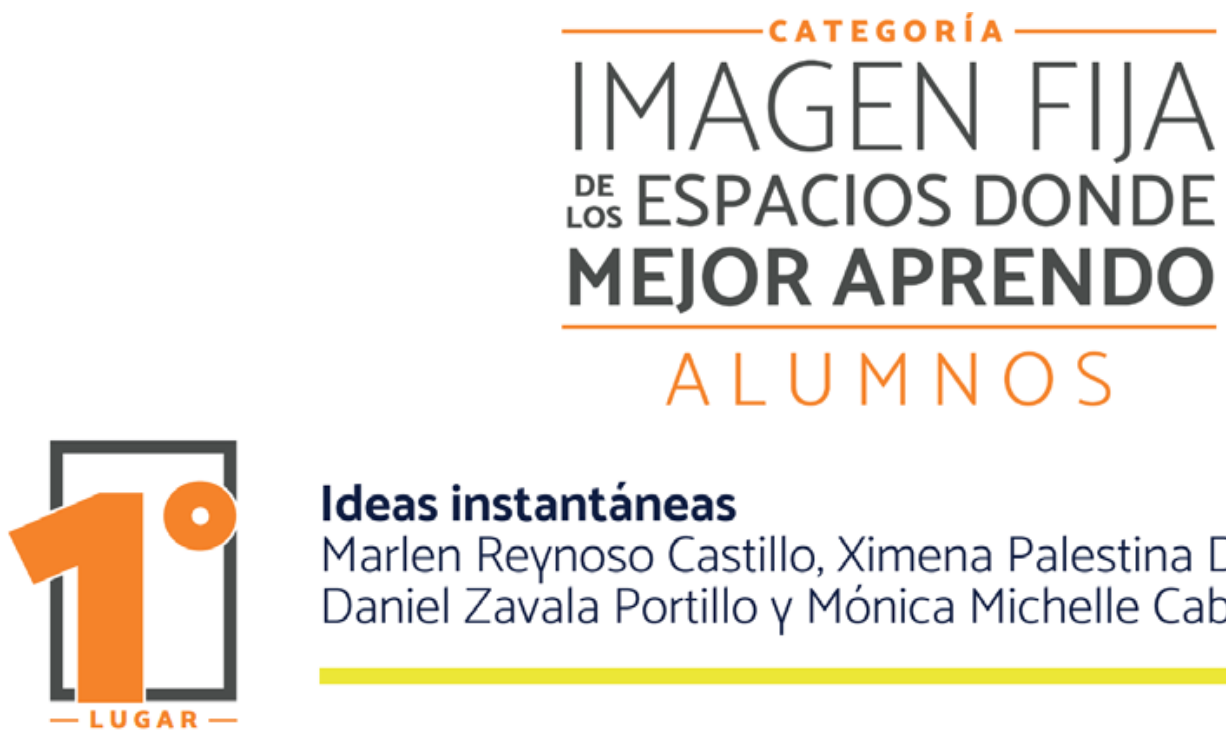

\section{Ideas instantáneas}

Marlen Reynoso Castillo, Ximena Palestina Domínguez, Daniel Zavala Portillo y Mónica Michelle Caballero González

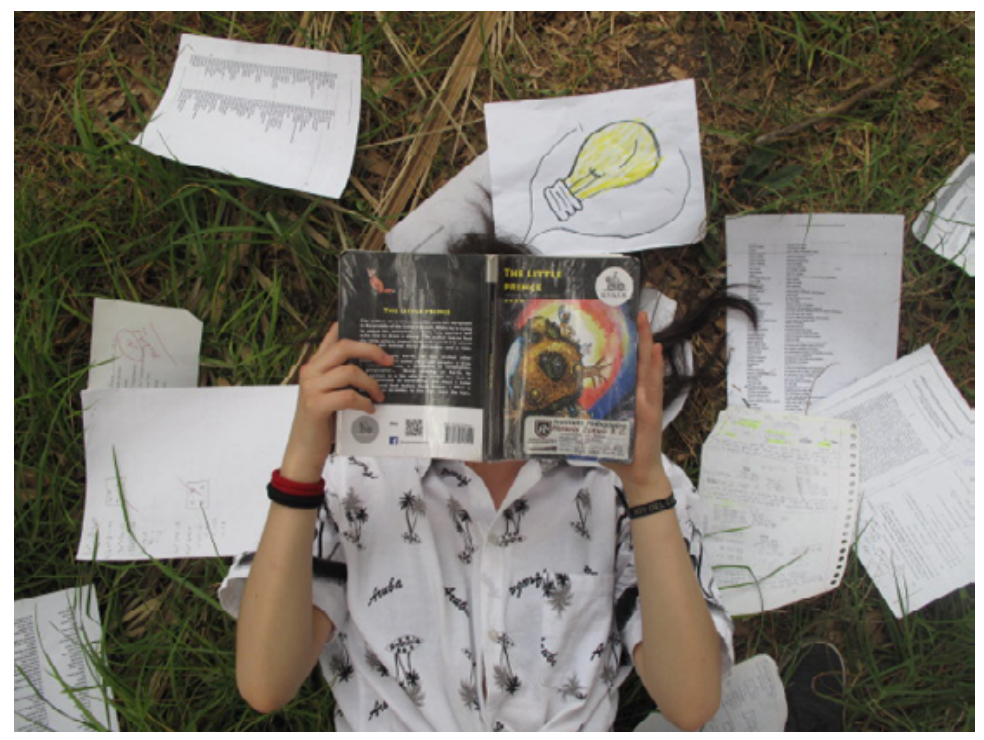

En las instalaciones de la UNAM, los lugares idóneos para adquirir aprendizajes son las muchas áreas verdes de los planteles. Leer y demás actividades se realizan con materiales proporcionados por la escuela. El apoyo de otros alumnos o docentes es útil. 


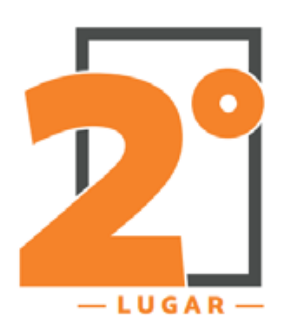

\section{El aprendizaje en la mirada Flor Arminda García Rea}

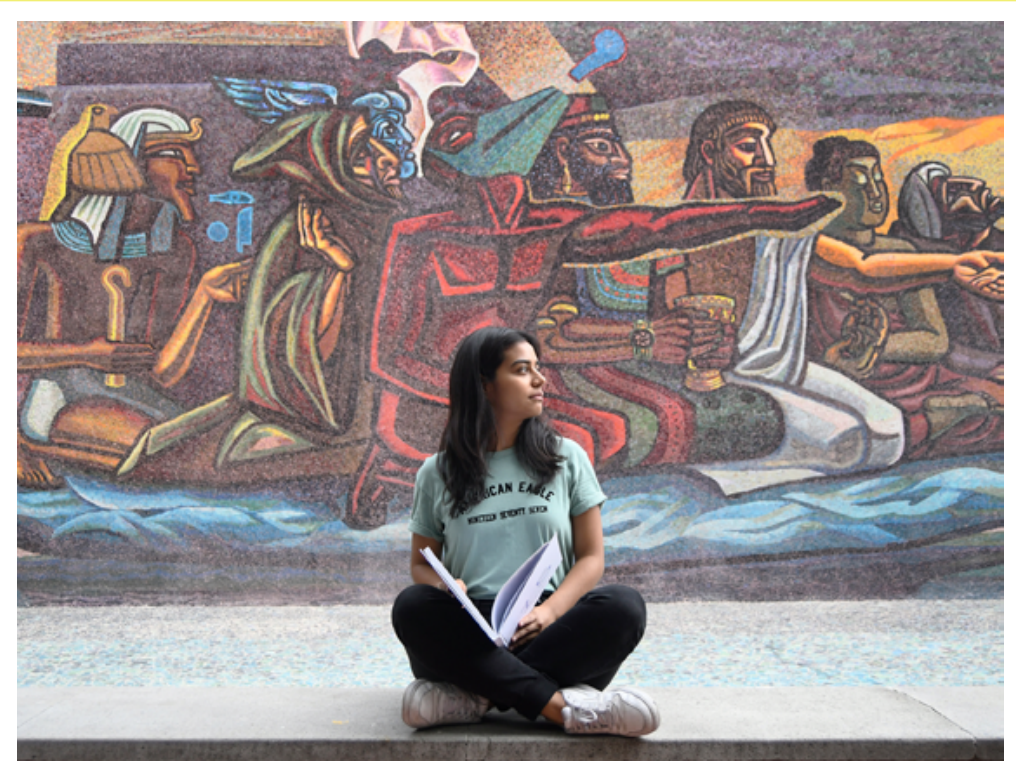

El aprendizaje va más allá de lo que adquirimos en el aula, nuestro crecimiento como universitarios también lo cultivamos de manera individual, tomados de la mano de nuestra historia y mirando hacia enfrente; abrazados por todos los espacios de nuestra universidad.

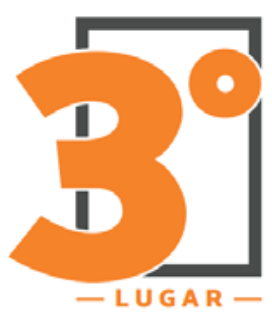

\section{Qué hago para aprender} Alejandra Rubi Hernández Conde

Para aprender es necesario muchas veces valerse de trucos a veces impensables, la imagen infiere que cada persona encuentra su propio método de aprendizaje y que la escuela proporciona todos los espacios y herramientas necesarias para lograr dicho proceso.

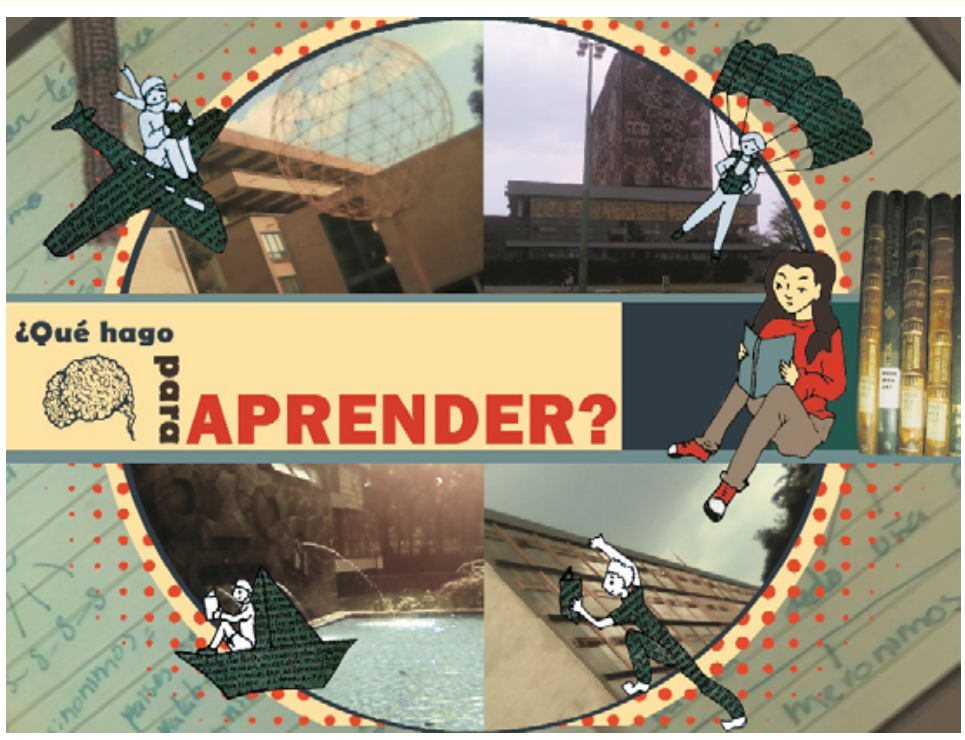




\section{Menciones honoríficas}

\section{Aprendizaje en Armonía Karen Yael Alcántara Ruiz, Elizabeth Martinez Bahena y Melba Haydee Hernández Ortiz}

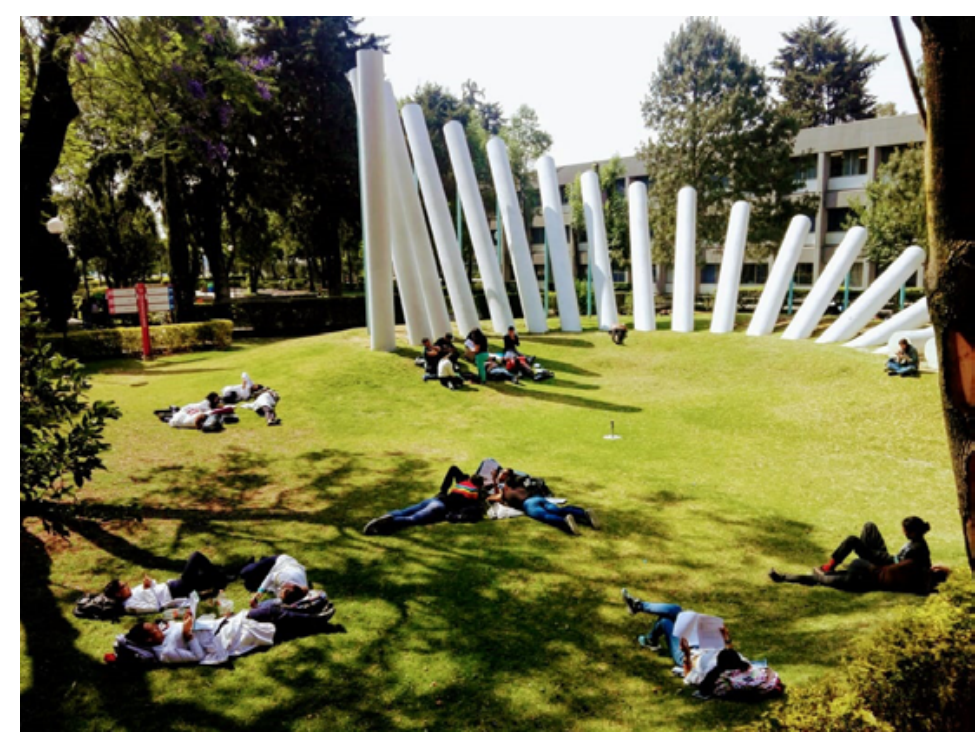

Aprendo junto a la "cerca caída" y sobre la verde alfombra que cubre mi facultad; aprendo con apuntes, libros y hasta celulares, pero más aprendo en compañía, pares, tercios o equipos; aprendo de mis compañeros y de las otras disciplinas.

\section{Una pequeña mirada al futuro Emma Amayrani Bautista Zúñiga}

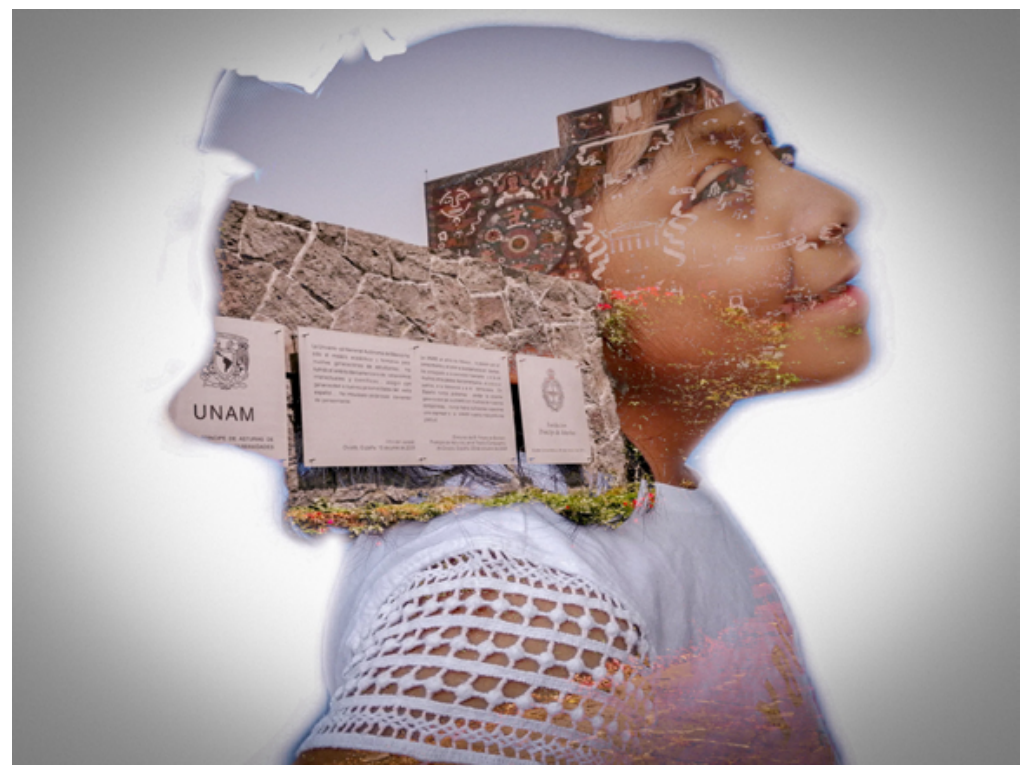

Busque capturar desde mi punto de vista el momento en que comenzamos a aprender, y esto es desde pequeños, fijando metas y sueños, es por ello que la silueta es de una pequeña mirando hacia arriba, con la imagen de la biblioteca central iluminando. 


\section{Dónde aprendo} Leslie Hernández Conde

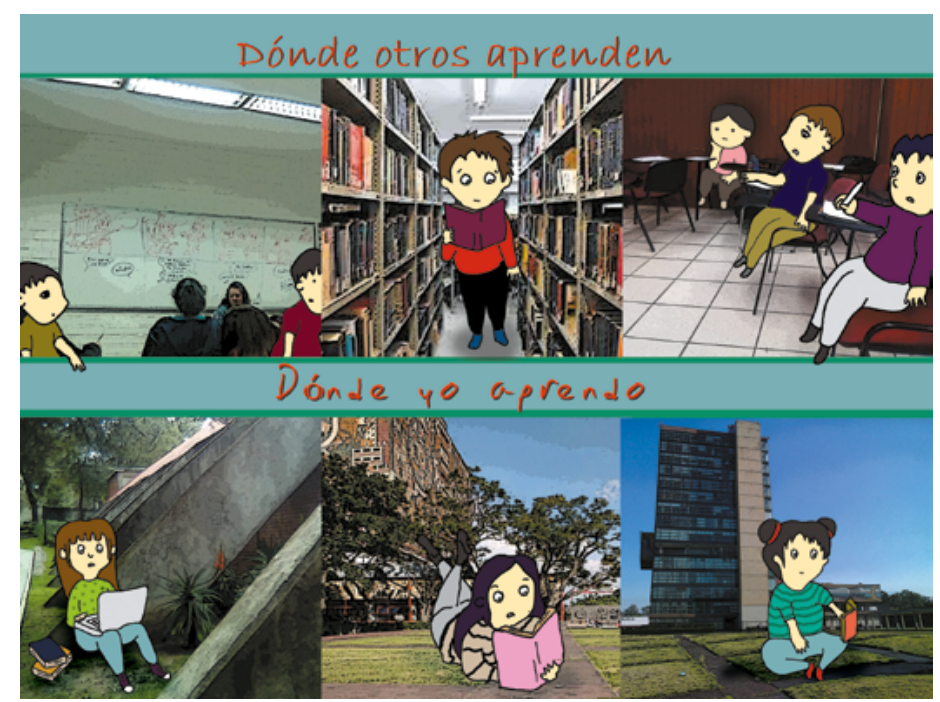

Esta imagen pretende transmitir que todas las personas somos diferentes. Hay diversidad de pensamientos, formas y lugares en que cada uno se siente cómodo estudiando, algunos preferirán sitios más sistemáticos: aulas o bibliotecas; mientras que otros preferimos lugares como los que elegí. 


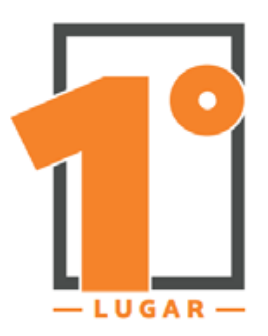

\section{Más allá del aula}

Berenice Martínez Cuatepotzo

- C A T E G O R Í A

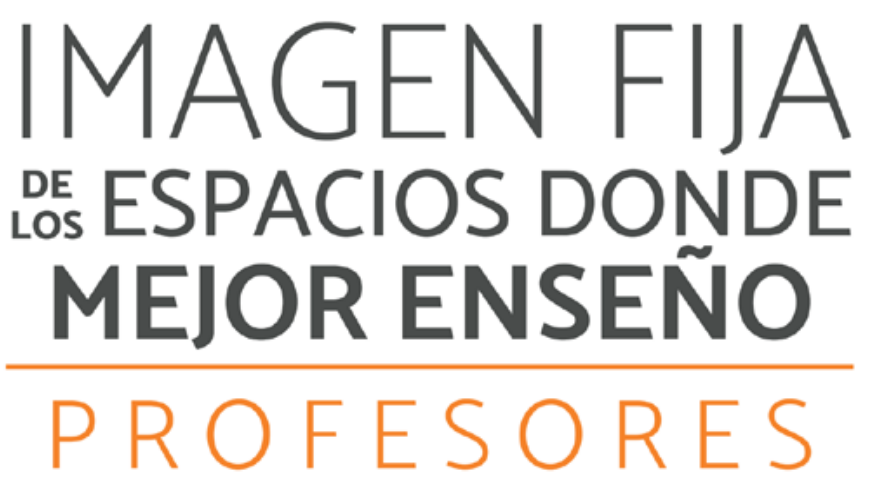

\begin{tabular}{l} 
DEESPACIOS DONDE \\
MEJOR ENSENNO \\
\hline PROFESORES
\end{tabular} 


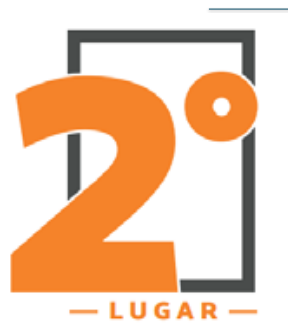

\section{Innovando en el "Aula CCHAerA" Erandy Gutiérrez García}

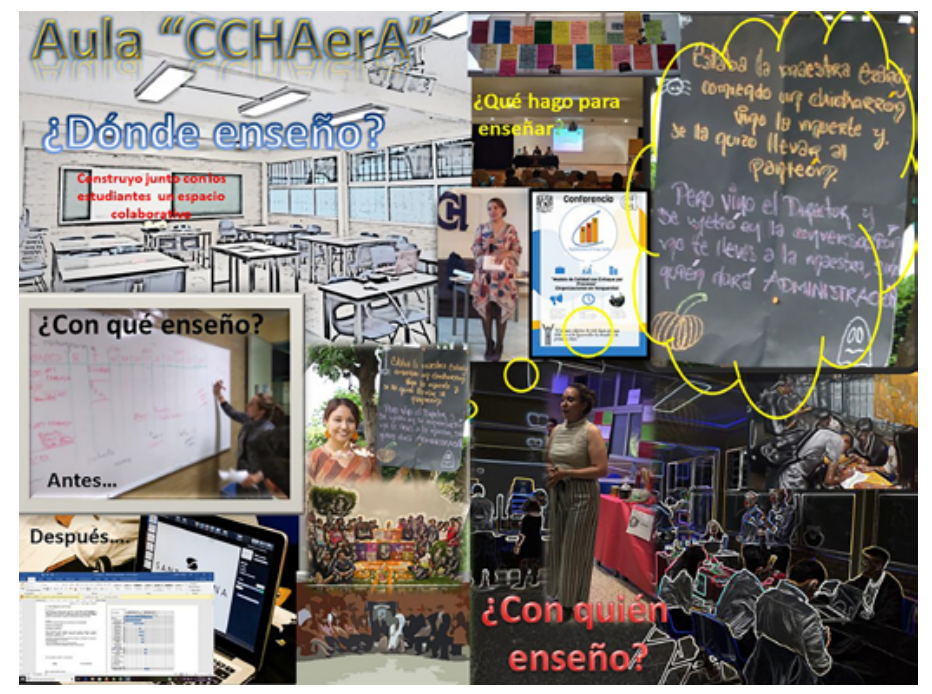

Compilación de imágenes expresando el quehacer de la práctica docente en CCH Azcapotzalco en específico de las asignaturas de Administración I y Il; con el título: Aula "CCHAerA". Innovando desde la construcción de un espacio colaborativo.

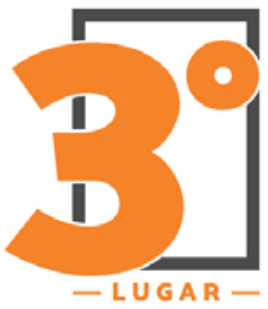

\section{"El salón que resguarda a todo" Sergio Aguilar Méndez}

El aula, el salón de clase, sigue siendo el mejor espacio en el que enseño. En la imagen pretendo reflejar que lo más relevante todavía es la interacción docente-alumnos (as), con apoyos como libros, dispositivos y al fondo el inicio de una presentación.

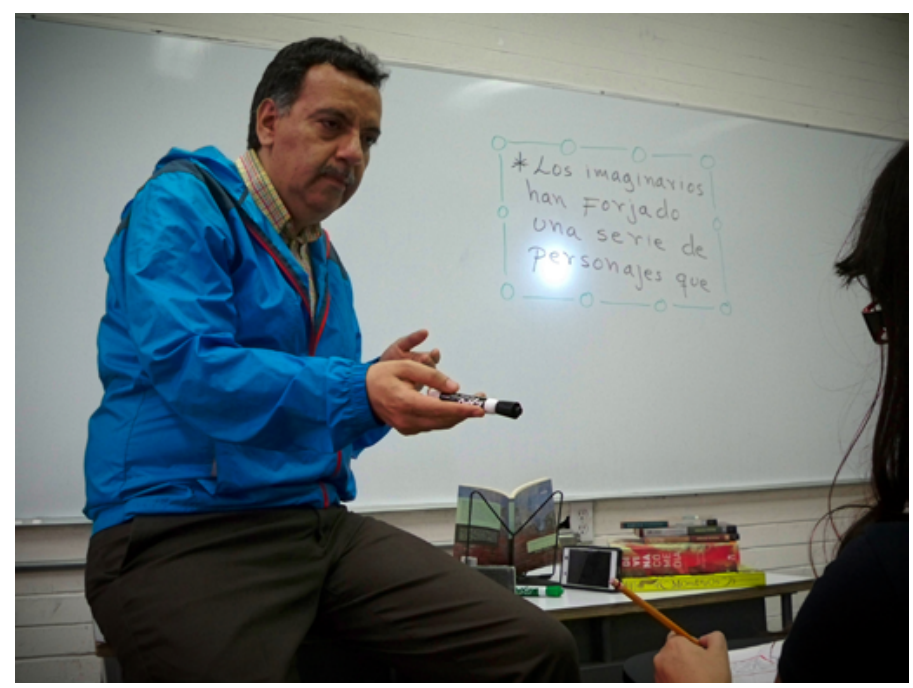




\section{Menciones honoríficas}

Espacios de innovación para la Enseñanza en la Facultad de Derecho Genoveva Verónica Rojo Sánchez y Martín Weinstein Y Stern

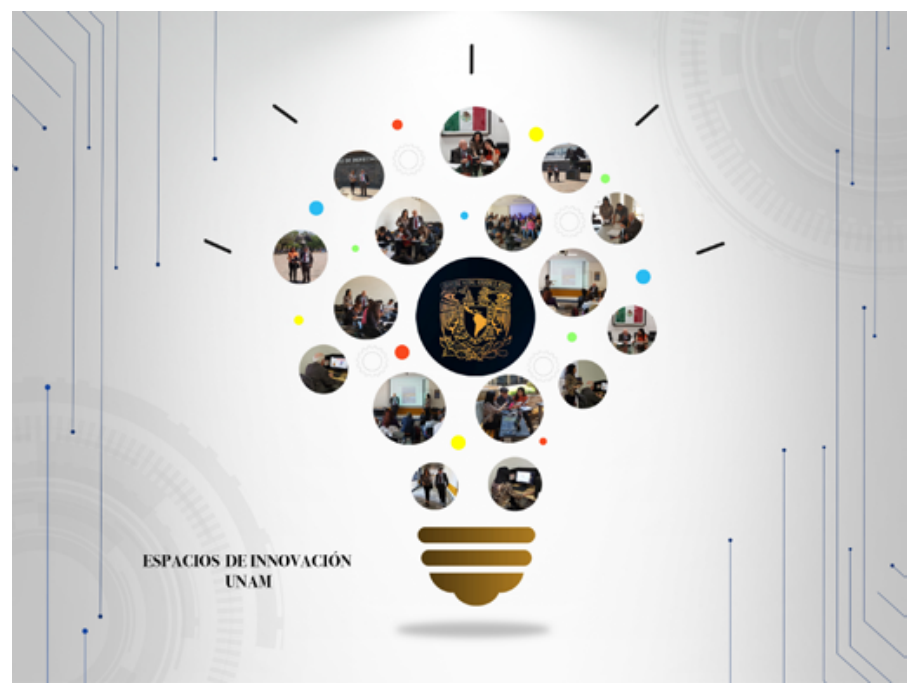

El conocimiento se enseña en diversos espacios de la Facultad de Derecho, utilizamos materiales didácticos y tecnología avanzada que fomenta la creatividad. El trabajo colaborativo de dos profesores fortalece a los alumnos del sistema escolarizado.

\section{Enseñando cirugía bucal Vallery Fuentes Arciniega}

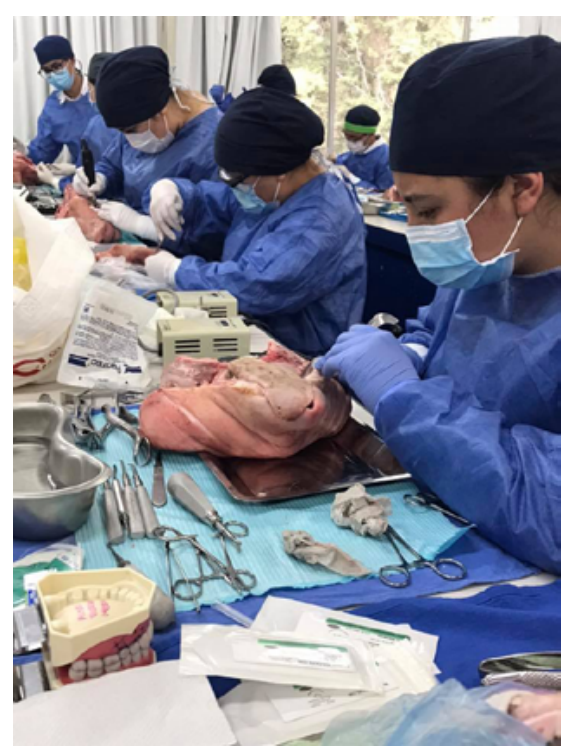

La práctica en las áreas quirúrgicas, permiten el desarrollo de habilidad, al mismo tiempo que se instruye en una formación apegada a normatividad con responsabilidad social y pasión. 


\section{Cómo citar este artículo}

* Prado Saavedra,Julio A.y González Flores, Patricia(2019).¿Dónde aprendo o enseño mejor? Concurso de imágenes fijas UNAM 2019. Revista Digital Universitaria (RDU). Vol. 20, núm. 4 julio-agosto. Dol: http://doi.org/10.22201/codeic.16076079e.2019. v20n4.a8.

Recepción: 25/06/2019 Aprobación: 25/06/2019. 